\title{
BLOOD GROUP POLYMORPHISM AND INBREEDING IN NATURAL POPULATIONS OF THE DEER MOUSE PEROMYSCUS MANICULATUS ${ }^{1}$
}

\author{
David I. Rasmussen ${ }^{2}$ \\ Mammalian Genetics Center, Department of Zoology \\ University of Michigan, Ann Arbor, Michigan
}

Accepted November 1, 1963

This study concerns an analysis of allelic and zygotic frequencies in natural populations of the woodland deer mouse, Peromyscus maniculatus gracilis (Le Conte). The genetic markers used in the study consist of two erythrocytic antigens which appear as unitary genetic characteristics inherited as a two-allele, one-locus system (Rasmussen, 1961).

The zygotic frequencies of the antigenic phenotypes indicate that association of gametes does not occur randomly within the deer mouse populations and an attempt to assess the gametic correlation and its basis in the genetic structure of the population is considered.

\section{ANTIgenic ChaRacters}

A detailed analysis of the genetic basis of the antigenic polymorphism and the immunological procedures used for ascertainment of the antigenic phenotypes has been reported by Rasmussen (1961). Two codominant alleles, designated $\mathrm{Pm}^{\mathrm{A}}$ and $\mathrm{Pm}^{\mathrm{B}}$, responsible for two antigenic characteristics, $A$ and $B$, defining three phenotypes ( $A, A B$, and $B$ ), were recognized by the use of reagents prepared from absorbed heteroimmune rabbit sera.

\section{LOCALITIES OF SAMPLES}

Samples from natural populations of the woodland deer mouse were trapped alive

\footnotetext{
1 This study is a portion of a thesis submitted to the University of Michigan for the degree of Doctor of Philosophy and was supported by a Graduate Genetics Traineeship (USPHS 26-71 C2S1) with aid from the NSF Graduate Student Research Fund, Rackham Graduate School.

${ }^{2}$ Present address: Department of Zoology, Arizona State University, Tempe, Arizona.
}

Evolution 18: 219-229. June, 1964 at the following localities in northern Michigan:

Shingleton-Nine mice were collected in September, 1960, in an immature beechmaple hardwood forest approximately 6 miles northeast of Shingleton, Alger County.

Munising-61 mice were collected in September, 1960, in a mature, near-virgin, hardwood forest approximately 0.5 mile east of Munising, Alger County.

Huron Mountains-A total of 166 mice were collected during June, 1961, from the Huron Mountain area, Marquette County. All individuals could be readily classified as "adults" or "juveniles" by means of pelage coloration. The "adults" are assumed to be survivors from the 1960 populations of the area. The "juveniles" are animals born during the spring of 1961 .

Two study plots within the Huron Mountain area were sampled. Each plot contained a grid of 196 traps covering an area of approximately 20 acres.

Plot \#1-86 mice were collected during six nights from a stand of virgin hardwoods, predominantly sugar maple, enclosing stands of hemlock. The plot was near the west shore of Lower Pine Lake and is similar to and continuous with the virgin hardwood plot described by Manville $(1949$, p. 18$)$.

Plot \#2-80 mice were collected during 5 nights in an area $3 / 4$ mile north of Ives Lake. The area consisted of a mixture of small hardwoods, hemlocks, white birch, and poplar with small open meadow areas. The center of the plot is the same birchpoplar area described by Manville (1949, p. 19). 


\section{Antigenic Polymorphism AND ALLELIC FREQUENCIES}

The allelic frequencies (table 1) are estimated directly from the frequency of zygotic types by maximum likelihood estimates (Cotterman, 1954). The standard errors of the estimated frequencies were computed assuming random union of gametes (Cotterman, 1954) and represent a minimal estimate of $s$, since if the samples were taken from inbreeding populations the variance is increased.

The assumption that only two alleles occur $(p+q=1)$, in the natural populations will be evaluated later.

The first sample of 76 individuals in table 1 shows the allelic frequencies in the laboratory stock of $P$. $m$. gracilis at the time of the isolation of the agglutination reagents, which was previous to the typing of about 600 individuals from the stock resulting from biased breeding to ascertain the genetic basis of the polymorphism.

The observed uniformity of frequencies (table 1), both between years and localities, is consistent with the supposition that the polymorphism represents a stable two-allele system maintained by a maximum intralocus fitness of the heterozygous type ( $\mathrm{Li}$, 1955b; Kimura, 1956). It is also of interest that the laboratory stock maintained the polymorphism, although during some pe- riods the number of animals in the stock became rather small.

\section{Zygotic Frequencies AND Gametic Correlation}

All samples from wild populations of $P$. $m$. gracilis exhibited a shortage of heterozygous individuals (or excess of homozygous types) from that expected with a two-allele panmictic equilibrium (tables 2 and 3 ).

Since the zygotic frequencies observed represent phenotypic frequencies rather than an absolute ascertainment of genotypic combinations, a number of explanations can be proposed for the observed results. The obvious possibilities include: (1) selective elimination of heterozygous individuals relative to the survival of the homozygous individuals, (2) positive phenotypic assortative mating, (3) phenotypically non-assortative inbreeding, and (4) the existence in the populations of a third allele, $\mathrm{Pm}^{\circ}$, which is not phenotypically recognizable. These explanations are not mutually exclusive, but the relative importance of each can, to some extent, be assessed.

No significant differences exist between sexes, ages, and areas of capture with respect to phenotypic frequencies observed (table 2), i.e., the contingency chi-squares

TABLE 1. Estimated allelic frequencies of antigenic types and standard errors (s) in various populations of Peromyscus maniculatus gracilis*

\begin{tabular}{lrccc}
\hline \multicolumn{1}{c}{ Sample } & $n$ & $\begin{array}{c}\text { freq } \mathrm{Pm}^{\mathrm{A}} \\
p \pm s\end{array}$ & $\begin{array}{c}\text { freq } \mathrm{Pm}^{\mathrm{B}} \\
q \pm s\end{array}$ & $\begin{array}{c}\text { Non-reactive } \\
\text { individuals observed }\end{array}$ \\
\hline $\begin{array}{l}\text { Laboratory stock Univ. of Michigan } \\
\text { (biased) }\end{array}$ & $\begin{array}{r}76 \\
\text { ca. } 600\end{array}$ & $\begin{array}{c}0.48 \pm 0.041 \\
\text { present }\end{array}$ & $\begin{array}{c}0.52 \pm 0.041 \\
\text { present }\end{array}$ & $\begin{array}{c}\text { none } \\
\text { none }\end{array}$ \\
Natural populations & & & & none \\
$\quad$ Shingleton (Sept., 1960) & 9 & $0.78 \pm 0.088$ & $0.22 \pm 0.088$ & none \\
Munising (Sept., 1960) & 61 & $0.66 \pm 0.043$ & $0.34 \pm 0.043$ & none \\
Huron Mountain (June, 1961) & & & & \\
$\quad$ Plot \#1 & 86 & $0.64 \pm 0.037$ & $0.36 \pm 0.037$ & none \\
$\quad$ Adults & 46 & 0.63 & 0.37 & \\
$\quad$ Juveniles & 40 & 0.65 & 0.35 & \\
$\quad$ Plot \#2 & 80 & $0.74 \pm 0.035$ & $0.26 \pm 0.035$ & \\
$\quad$ Adults & 39 & 0.76 & 0.24 & \\
$\quad$ Juveniles & 41 & 0.73 & 0.27 & \\
\hline
\end{tabular}

* Assuming: $p+q=1$; frequency of $\mathrm{Pm}^{\mathrm{A}}$ allele equals $p$; frequency of $\mathrm{Pm}^{\mathrm{B}}$ allele equals $q$. 
for homogeneity are as follows: three major areas $\times$ three phenotypes, $\chi^{2}=4.83$, d.f. $=4, P>0.25$; two sexes pooled from all areas $\times$ three phenotypes, $x^{2}=1.85$, d.f. $=2, P>0.30$; two ages from the Huron Mountain areas $\times$ three phenotypes, $\chi^{2}=0.62$, d.f. $=2, P>0.70$.

The statistically homogeneous allelic frequencies and zygotic proportions in the populations indicate that a selective disadvantage of the heterozygote is not the cause of the shortage of the heterozygous types $(\mathrm{Li}, 1955 \mathrm{~b})$.

The possibility of antigenic phenotypic assortative mating among the mice appears remote. It is therefore assumed that any non-random mating which occurs within the populations is due to relationships of mates only.

Inbreeding and the presence of an unrecognized recessive allele are not mutually exclusive causes of the zygotic frequencies observed, but can be considered separately or in combination in four model systems. Table 3 indicates four possible models of zygotic frequencies that explain the observed frequencies. All of the models are special cases of Model IV, with reference to random or non-random mating populations containing either two alleles $\left(\mathrm{Pm}^{\mathrm{A}}\right.$, and $\left.\mathrm{Pm}^{\mathrm{B}}\right)$ or three or more alleles $\left(\mathrm{Pm}^{\mathrm{A}}\right.$,

TABLE 2. Numbers of individuals of phenotypes observed and estimates of gametic correlations of natural populations of Peromyscus maniculatus gracilis

\begin{tabular}{|c|c|c|c|c|c|}
\hline \multirow[b]{2}{*}{ Sample } & \multicolumn{4}{|c|}{ Number observed } & \multirow{2}{*}{$\underset{f \pm s}{\text { Gametic }}$ correlation $_{f \pm s}$} \\
\hline & $\underset{n}{\text { Total }}$ & $\underset{a}{\text { Type A }}$ & Type $\mathrm{AB}$ & $\underset{c}{\text { Type } B}$ & \\
\hline \multicolumn{6}{|l|}{ MunisIng } \\
\hline Total & 61 & 29 & 22 & 10 & $0.201 \pm 0.129$ \\
\hline Females & 35 & 16 & 12 & 7 & $0.266 \pm 0.167$ \\
\hline Males & 26 & 13 & 10 & 3 & $0.097 \pm 0.205$ \\
\hline \multicolumn{6}{|c|}{ Huron Mountains Area \#1 } \\
\hline Total & 86 & 39 & 32 & 15 & $0.193 \pm 0.108$ \\
\hline Females & 52 & 23 & 19 & 10 & $0.221 \pm 0.138$ \\
\hline Males & 34 & 16 & 13 & 5 & $0.146 \pm 0.174$ \\
\hline Adults & 46 & 21 & 16 & 9 & $0.254 \pm 0.146$ \\
\hline Females & 27 & 11 & 9 & 7 & 0.318 \\
\hline Males & 19 & 10 & 7 & 2 & 0.104 \\
\hline Juveniles & 40 & 18 & 16 & 6 & $0.121 \pm 0.160$ \\
\hline Females & 25 & 12 & 10 & 3 & 0.081 \\
\hline Males & 15 & 6 & 6 & 3 & 0.167 \\
\hline \multicolumn{6}{|c|}{ Huron Mountains Area \#2 } \\
\hline Total & 80 & 49 & 21 & 10 & $0.311 \pm 0.119$ \\
\hline Females & 45 & 27 & 11 & 7 & $0.391 \pm 0.145$ \\
\hline Males & 35 & 22 & 10 & 3 & $0.190 \pm 0.197$ \\
\hline Adults & 39 & 25 & 9 & 5 & $0.374 \pm 0.171$ \\
\hline Females & 24 & 15 & 5 & 4 & 0.472 \\
\hline Males & 15 & 10 & 4 & 1 & 0.167 \\
\hline Juveniles & 41 & 24 & 12 & 5 & $0.255 \pm 0.165$ \\
\hline Females & 21 & 12 & 6 & 3 & 0.300 \\
\hline Males & 20 & 12 & 6 & 2 & 0.200 \\
\hline Pooled & 227 & 117 & 75 & 35 & $0.291 \pm 0.067$ \\
\hline
\end{tabular}

* The estimates of gametic correlation $(f)$ assume Model III (in table 3). The derivation of the standard errors $(s)$ of the estimates is given in the appendix. 
$\mathrm{Pm}^{\mathrm{B}}$, and $\mathrm{Pm}^{\circ}$ ) at the locus, where $\mathrm{Pm}^{\mathrm{O}}$ represent all non- $\mathrm{Pm}^{\mathrm{A}}$, non- $\mathrm{Pm}^{\mathrm{B}}$ alleles.

Chi-square values and their respective probabilities of fit to Models I and II are listed in table 3.

Model I can be tested by the fit of the observed frequencies to the expected panmictic two-allele model (Cotterman, 1954).

Model II can be tested using Bernstein's method (Stevens, 1950; Kempthorne, 1957). With the pooled data (table 2) the estimates of the allelic frequencies, using Model II, are as follows: $p=0.641$, $q=0.297, r=0.059$. Model II can be rejected using the pooled data with a probability of error of less than 0.01 .

The analysis indicates that the assumption of panmixia $(F=0)$ can be safely rejected (Models I and II, table 3 ).

No test of fitness of the data to Model III can be applied in the absence of direct evidence indicating the existence of a third allele. Since it is assumed in Model III that $p+q=1$ and that the zygotic proportions observed are attributable to correlation of uniting gametes, the empirical data can be used to provide an estimate of inbreeding expressed in terms of the value of the mean gametic correlation $(F)$ within the populations ( $\mathrm{Li}$ and Horvitz, 1953).

Estimates of $F$ (denoted by $f$ ) and the standard errors of the estimates for the various populations sampled are given in table 2. The 95\% level confidence intervals of the estimate of $F$ for the pooled sample are $f=0.117$ to 0.474 .

With the lack of direct evidence of a third allele in the population, Model III can be used to explain the observed zygotic frequencies. In addition to the lack of a non-reactive phenotype in the trapped samples, there is additional evidence regarding the lack of a third recessive allele in the observed samples. By the nature of

TABLE 3. Expected zygotic proportions and statistical fit of observed zygotic proportions

\begin{tabular}{|c|c|c|c|c|c|}
\hline \multirow{4}{*}{$\begin{array}{l}\text { Observed } \\
\text { phenotype }\end{array}$} & \multirow{4}{*}{$\begin{array}{c}\text { Observed } \\
\text { frequency }\end{array}$} & \multicolumn{4}{|c|}{ Models of expected frequencies } \\
\hline & & I & II & III & IV \\
\hline & & \multicolumn{2}{|c|}{ No inbreeding } & \multicolumn{2}{|c|}{ Inbreeding } \\
\hline & & $p+q=1, F=0$ & $p+q+r=1, F=0$ & $p+q=1, F>0$ & $p+q+r=1, F>0$ \\
\hline A & $a / n$ & $p^{2}$ & $p^{2}+2 p r$ & $p^{2}+F p q$ & $\begin{array}{c}p^{2}+F p q+F p r \\
\quad+2 p r(1-F)\end{array}$ \\
\hline $\mathrm{AB}$ & $b / n$ & $2 p q$ & $2 p q$ & $2 p q(1-F)$ & $2 p q(1-F)$ \\
\hline $\mathrm{B}$ & $c / n$ & $q^{2}$ & $q^{2}+2 q r$ & $q^{2}+F p q$ & $\begin{array}{c}q^{2}+F p q+F q r \\
\quad+2 q r(1-F)\end{array}$ \\
\hline 0 & $d / n$ & not expected & $r^{2}$ & not expected & $r^{2}+F p r+F q r$ \\
\hline \multicolumn{4}{|c|}{ Chi-square values and probability of fit for Models I and II } & Standard & Maximum likeli- \\
\hline & errors of the & hood estimates \\
\hline \multicolumn{4}{|c|}{$\begin{array}{l}\text { d.f. }=1 \quad n=61 \\
\end{array}$} & estimates of & on total \\
\hline $\begin{array}{l}\text { Huron } \\
\text { d.f. }=\end{array}$ & $\begin{array}{l}\text { Mtn. } \# 1 \\
1 \quad n=86\end{array}$ & $3.00 P<0.10$ & $2.41 P<0.15$ & $\begin{array}{l}F \text { given in } \\
\text { table } 2\end{array}$ & \\
\hline \multicolumn{6}{|c|}{ Huron Mtn. $\# 2$} \\
\hline d.f. $=$ & $1 \quad n=80$ & $7.75 P<0.01$ & $4.47 P<0.05$ & & $p=0.680$ \\
\hline \multicolumn{6}{|c|}{$\chi^{2}$ on total } \\
\hline d.f. $=$ & $1 \quad n=227$ & $13.08 P<0.001$ & $7.14 P<0.01$ & & $q=0.319$ \\
\hline \multicolumn{6}{|c|}{ Sums of $\chi^{2}$} \\
\hline d.f. $=$ & & $13.23 P<0.01$ & $8.24 P<0.05$ & & $r=0.001$ \\
\hline \multicolumn{6}{|c|}{ Heterogeneity $\chi^{2}$} \\
\hline \multicolumn{2}{|c|}{$\begin{array}{l}\text { d.f. }=2 \\
\text { Heterogeneity } \chi^{2}\end{array}$} & $0.15 P>0.90$ & $1.10 P>0.50$ & & $f=0.246$ \\
\hline \multicolumn{2}{|c|}{ d.f. $=1 *$} & $0.15 P>0.50$ & $1.10 P>0.25$ & & \\
\hline
\end{tabular}

* Most heterogeneous partitioning obtained by assuming all heterogeneity is contained in one sample. 
the hypothesis of Model III this evidence must be negative and the absolute establishment of inbreeding alone as the cause for observed zygotic frequencies is impossible with the present data. No non-reactive phenotype was observed in a total of 70 offspring from 16 wild-trapped gravid females from the Huron Mountain plots. A total of 43 offspring from six type $A$ by type $B$ matings of wild-trapped mice were typed and all offspring were type $A B$, indicating homozygosity of the monotypic parents. Other less diagnostic matings also lacked evidence suggesting a third allele in the feral mice.

Maximum likelihood estimates for the variables $p, q, r$, and $F$ (Model IV) were calculated for the pooled data by the method of Schull, Ito, and Soni (in press). The estimates are: $p=0.680, q=0.319$, $r=0.001$, and $f=0.246$. No confidence limits can be calculated.

In view of the evaluation of the models, gametic correlation due to population inbreeding appears the primary cause of the phenotypic frequencies observed. The actual value of gametic correlation $(F)$ for the populations may be less than the estimated values owing to the presence of a third allele as a very low frequency (i.e., 0.001 ). However, if heterozygotes are favored by selection, then $F$ would be even greater than the estimates calculated.

\section{The Value of $F$ and Effective Population Size}

The knowledge of the genetical structure of natural populations is very limited and attempts to gather such data can impose great practical problems. In the case of terrestrial vertebrates, however, any general concept of effective population size has developed largely in the absence of empirical estimates or evaluations of the genetic structure of populations.

Estimates of the genetically effective population size $(N)$ can be derived only by indirect methods in natural populations of most species. The total population number implies only an upper limit on the value of
$N$ and the disparity between the two concepts of population size may be rather great in populations of small mammals.

As stated by Wright (1943), the inbreeding, measured by $F$, may be of either of two extreme sorts: (1) sporadic mating of close relatives owing to short-range dispersal (as a functional relationship to density), with no physical fragmentation of the population into subgroups (Isolation by Distance), or (2) division into partially isolated subgroups, within each of which there is random mating (Island Structure).

In an attempt to estimate an order of magnitude of $N$ in the populations of the deer mouse studied, the attributes of two of the model populations devised by Wright (1943, 1946, 1951) are used as reference models for the data. The value of $F$ for a total population increases in time (generations) in a finite population (see detailed discussion by Wright [1951]). Under any given population structure (a value of $N$ and a dispersion pattern) the value of $F$ approaches an asymptote which is less than one, if the rate of addition of "new" or "foreign" genetic material $(m)$ is greater than zero. Assuming that the value of $F$ estimated in the populations represents that of an equilibrium or asymptotic value, the effective population size $N$ can be calculated for any given value of $m$ utilizing an assumed model of the population.

Island model of structure.-This model represents the total population as an array of divided island breeding populations of size $N$, replenished at the rate $m$ by randomly drawn genetic material from the other islands. The relationship of the limiting value of $F, m$, and $N$ is given by Wright (1943, 1951).

The structure of the island model is certainly not met by the populations of deer mice studied, but the model would tend to indicate a situation of maximal genetic isolation and discontinuity between breeding units within the population. Given a value of $F$ (in this case the estimated 


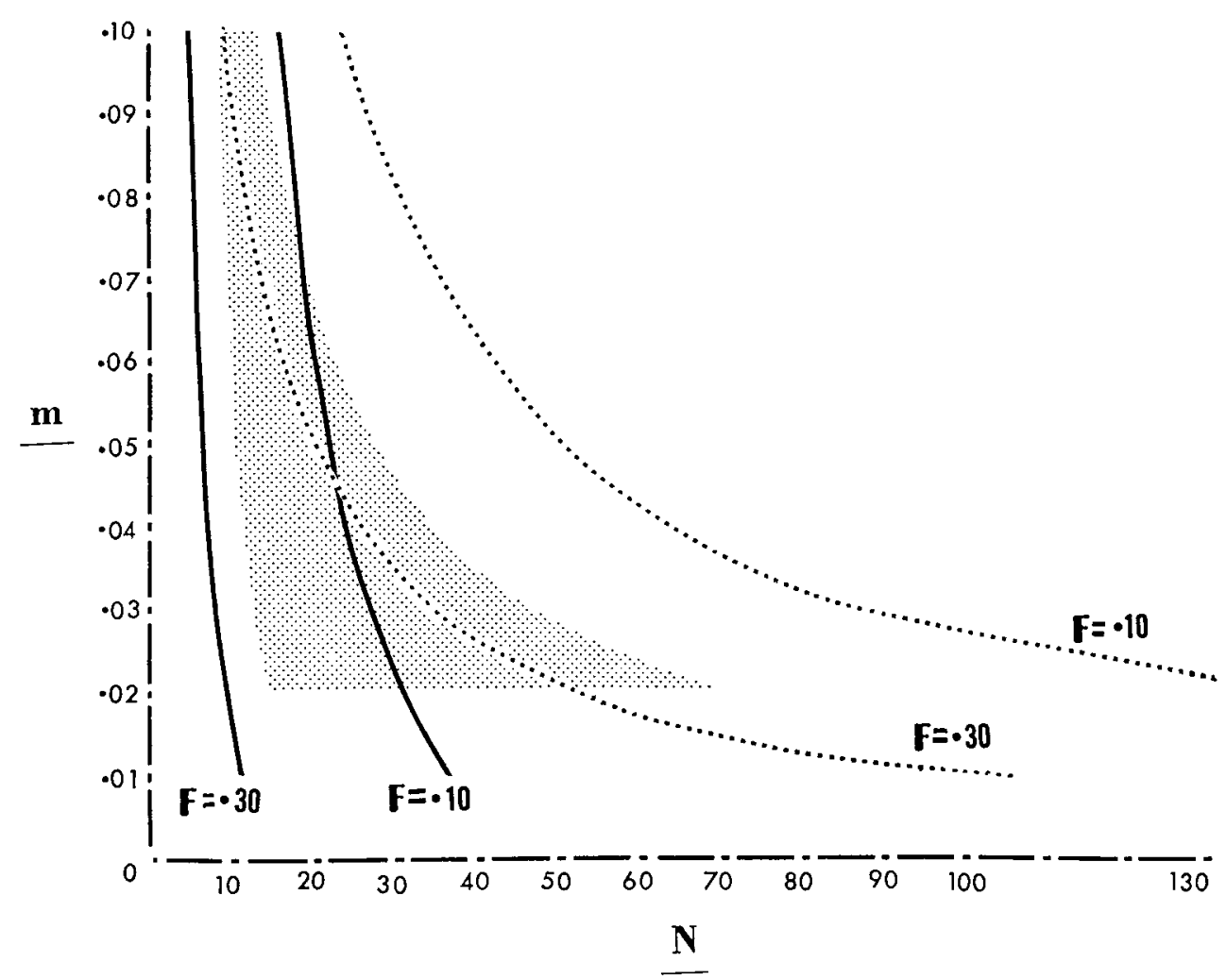

FIG. 1. Asymptotic values of gametic correlation $(F)$. Vertical axis $(m)$, input rate of non-neighborhood alleles; horizontal axis $(N)$, size of panmictic unit or neighborhood. Solid lines, Wright's isolation by distance model; dotted lines, Wright's island model; shaded area lies between $F=0.20$ for both models.

parameter), the value of $N$ for any value of $m$ would overestimate the genetically effective size within the mouse populations. Fig. 1 shows the family of curves ( $F=$ $0.1,0.2,0.3$ ) for this model.

Isolation by distance.-In this model the randomness of gene exchange is limited by the distance of dispersal (from birth to mating) of an individual. The assumption of uniform dispersion of individuals is necessary for the development of the model. In the case of uniform distribution over a continuous area the asymptotic value of $F$ is given by Wright (1951).

The family of curves $(F=0.1,0.2,0.3)$ for the isolation by distance model is shown in fig. 1 for various values of $m$ and $N$.

The spatial relationship of mice within the areas sampled appears to approximate more closely (as compared to the island model) the assumed uniform dispersion of Wright's distance model. Extensive literature on the species Peromyscus maniculatus and some studies of $P . m$. gracilis in hardwood forests of northern Michigan (Manville, 1949; Blair, 1942) suggests that home range and territorial behavior of the species lead toward the development of a uniform pattern of dispersion within a suitable uniform habitat. Clumping within this general pattern occurs due to family groups within home ranges, local variations in habitat, and other fragmenting influences. Therefore, the two model populations of Wright would approximate the limits of the population structure and dispersion pattern of these natural populations 
of deer mice. The observation of apparent uniform habitats does not preclude the possibility that animals within such areas inhabit discontinuous and localized portions of the total area.

Although no direct estimate of $m$ is available, the continuity of mice within the trapping areas suggests this parameter is sizable (i.e., $m>0.01$ ) and the estimated values of $F$ should be attributable to a small neighborhood size of the order $N=$ 10 to 75 . The shaded area of fig. 1 indicates a judgment of the most probable area in which the natural populations of the deer mice are defined in terms of the two parameters, $m$ and $N$. The populations sampled are not isolates and the trapping areas were continuous with extensive areas suitable for habitation of the deer mouse. On the basis of these observations, and the acceptance of the estimated values of $F$, it is assumed that the rather restricted breeding structure of such large continuous populations is primarily a result of mating and dispersal behavior from birth to mating site within the populations (approaching Wright's distance model) rather than physiographic and ecological discontinuities imposing a structure of well defined "island" subgroups on the population.

The above estimates of the size of the panmictic unit, as well as the previous estimates of $F$, are derived from the analysis of zygotic frequencies at a single locus. The numerous necessary assumptions attest to the fact that such estimates can be considered only as indications of the general ranges of magnitudes of these population parameters. The effects of density changes, selection, and possible presence of unidentified recessive alleles on the above estimates are impossible to evaluate completely. The conceptual models relating $N$ and $F$ may be rigorously described, but the practical difficulties of interpreting empirical data from natural populations remain rather formidable.

\section{Other Data on Peromyscus} Populations

Blair (1947) estimated the frequencies of coat color genes in populations of $P . m$. blandus from New Mexico. The zygotic frequencies observed in his study displayed a slight excess of heterozygous types as compared with the expected frequencies of a two-allele panmictic model (Model I), although the observed deviation was not significant $(P>0.25)$. These results are contrary to the observations here reported in respect to population panmixia.

Howard (1949) performed an extensive study of dispersal and demography of a population of prairie deer mice, $P . m$. bairdii, in southern Michigan. Although the woodland deer mouse and prairie deer mice differ markedly in morphology and habitat preference, some interesting correlations between the findings of Howard and the present study can be noted.

During the study by Howard, a number of consanguineous matings were observed. Howard estimated "that at least 4 to 10 percent of litters observed were produced by parent-offspring matings or matings between sibs." A minimal estimate of $F$ can be derived by the method of Dahlberg (Dahlberg, 1948, p. 61; Li, 1955a, p. 229), giving an estimate of gametic correlation for the population of $f=0.010$ to 0.025 from the data observed by Howard. This estimate ignores all consanguinity other than the observed parent-offspring and sib matings. Since multiple relationship matings through numerous generations would be expected to be the major contributor to the value of $F$ for the total population, it is of interest to note that the amount of inbreeding observed by Howard was limited to a minimal number of generations (less than six) during the period of study.

A crude estimate of the size of the panmictic unit $(N)$ can be derived using observation of the size of subunits within $N$ and frequency of matings within these subunits. This estimate requires an assumption of equal frequencies of males and females within $N$ and within the subunits. Since a given mating within a panmictic unit occurs at a probability of $1 /(N-1)$ for bisexual organisms, the probability of 
a mating within any observed subunit of $N$ is $(L-1) /(N-1)$, where $L$ is the size of the subunit. The size of the panmictic unit can be estimated by the equation $N=[S(L-1) / x]+1$, where $x$ is the observed frequency of within subunit matings $[x$ estimate of $(L-1) /(N-1)]$. The value of $S$ is the probability of survival of individuals of the subunit from the time of the observed size of $L$ to the time of the observation of the frequency $(x)$ of mating between individuals of this unit. The mean litter size given by Howard is 3.64, so that the value of $L=5.64$ assuming sibs and parents are part of a subunit of the same neighborhood. Assuming $S=1$, an unreal assumption tending to maximize the estimate of $N$, the estimated value of $N$ varies from $N=117$ to $N=47$ for the observed values of $x$ from 0.04 to 0.10 . This estimate is generally inefficient since almost certainly the value of $S$ is less than one and the sibmating frequencies of Howard perhaps include within and between litter sibmatings. The pooling of parents (already mated) with non-mated litter members also biases the data, but was necessary because the definition of the observed value of $x$. In addition, the practical problems of estimating $x$ would tend to make an observed $x$ less than the actual value of $x$. However, the general range of this estimated $N$ agrees with those of the $P$. $m$. gracilis data when assuming $S<1$, and suggests a restricted neighborhood size.

Wright $(1943,1946)$ has given a method of relating the value $N$ to the variance of the distance of dispersal of parents $\left(\sigma^{2}\right)$ from birth to breeding site. The number of individuals comprising the neighborhood $(N)$ is given by $N=4 \pi \sigma^{2} d$, where the density $(d)$ is expressed as $d=n / 4 \sigma^{2}$, such that $N=n \pi(n=$ number of individuals in unit area of $\left.4 \sigma^{2}\right)$. Assuming a normal distribution, this circle of the radius $2 \sigma$ will include $86.5 \%$ of the parents of individuals at the center, or similarly $86.5 \%$ of individuals born in the center will breed within an area enclosed by a circle of the radius $2 \sigma$. This calcula- tion of $N$ results in a migration rate of $m=0.135$.

Using the dispersal data published in tabular form by Dice and Howard (1951), it is possible to estimate a value of $N$. The distribution curve of the dispersal distances observed is skewed toward minimal dispersal and also show a greater frequency of long-distance dispersers in comparison with the normal curve assumed in Wright's model. The variance of the mean dispersal distance of the 135 mice ( 71 males and 64 females) equals 514,005 square feet $\left(=s^{2}\right)$. A circle of radius $2 s(=1,450$ feet) for the observed data includes $92.4 \%$ of the breeding sites of animals born at its center, as compared to the $86.5 \%$ included in the circle of $2 \sigma$ radius assumed in the model of Wright. Therefore, the use of the observed $2 s$ value would only slightly bias the estimate of $N$ to overestimate the actual neighborhood size using $N=4 \pi s^{2} d$ and $m=0.135$ for the observed data.

Using extreme values for the density of mature mating individuals of one mouse per 12 acres to one mouse per 1.5 acres (estimated from the size of the study area and the monthly changes of numbers noted by Howard [1949]), estimates of the panmictic unit vary from $N=12.4$ to $N=$ 98.8 .

These estimates exhibit a close resemblance to those estimated from the zygotic frequencies of the populations of $P . m$. gracilis (fig. 1) and further suggest a limited neighborhood size of this natural population.

\section{Discussion}

Evidence from natural populations of the woodland deer mouse, $P . m$. gracilis, and previously published investigations of natural populations of the prairie deer mouse, P. m. bairdii (Howard, 1949; Dice and Howard, 1951), suggest that within populations of these small mammals a large disparity exists between the total population size and the genetically effective size. Species populations are usually not pan- 
mictic, and the present evidence suggests that the exchange of genetic material within local populations (even when continuous with neighboring populations) need not approach panmixia.

The theoretical foundation of advantages of a fine-scaled structure of partial isolation for evolutionary transformation have been extensively discussed by Wright (1940, 1948, 1951, 1960). The population structure estimated in this study indicates that the joint effects of systematic and random processes acting simultaneously may not be as deterministic in what are considered common or non-isolated populations of mammals as would be expected if panmixia were incorrectly assumed.

The naturalists and ecologists have long seen a spatial structuring of animal populations with studies of home range, territoriality, localized breeding places, and the return to neighborhood of birthplace by migrating populations. These observations have been given valid adaptive significance in terms of food finding, mate finding, and habitat finding, but the genetic consequences of such behavior may also have significant roles in the genetic structure of populations, in the applicability of the concept of panmixia, and in the evolutionary mechanisms which operate under variously structured systems.

\section{SUMMARY}

1. Frequencies of the alleles determining an antigenic polymorphism in the deer mouse, Peromyscus maniculatus, have been estimated for various natural populations.

2. In large samples of the woodland deer mouse, $P$. $m$. gracilis, from northern Michigan, a significant shortage of heterozygous individuals was observed.

3. Analyses indicate that the shortage of heterozygous individuals is due to gametic correlation (of the order $F=0.10$ to 0.30 ) resulting from inbreeding within the populations.

4. The size of the panmictic unit within these continuous, non-isolate popu- lations is estimated to be of the order of 10 to 75 individuals.

5. Previously published data of dispersal and consanguinity in the deer mouse (Howard, 1949; Dice and Howard, 1951) are shown to indicate the same level of inbreeding.

6. Evolutionary aspects of the genetical structure of these natural populations are discussed.

\section{ACKNOWLEDGMENTS}

I extend my gratitude to the following staff members of the University of Michigan for their aid and valuable suggestions during the period of the study and analysis of the data: Dr. Morris Foster, Dr. Elizabeth Barto, and Dr. E. T. Hooper of the Department of Zoology, Dr. H. Gershowitz and Dr. W. J. Schull of the Department of Human Genetics. I especially thank Dr. Foster for his valuable suggestions and criticisms concerning the preparation of the manuscript. The hospitality of the personnel of the Cusino Wildlife Experiment Station during the 1960 field study and of the Huron Mountain Club Wildlife Association during the summer of 1961 is graciously appreciated. The assistance of Mr. J. R. Winkelman in the field during the summer of 1961 is thankfully acknowledged.

\section{Appendix}

Variance of the maximum likelihood estimates of gametic correlation.-Consider a mating population with respect to a single locus, where $p$ and $q$ are the allelic frequencies $(p+q=1$, Model III, table 3 ) and $F$ the gametic correlation. Taking $p$ and $F$ as the independent parameters, the maximum likelihood estimates of the two variables are given by Neel and Schull (1954) and $\mathrm{Li}$ and Horvitz (1953), respectively.

The variance of these estimates can be obtained from the inverse of the "information matrix" or the matrix of the second partial derivatives of the expected values; thus, 


$$
V=I^{-1}=\left|\begin{array}{l}
I_{p p} I_{p F} \\
I_{p F} I_{F F}
\end{array}\right|^{-1}=\left|\begin{array}{ll}
I_{\mathrm{FF}} / \Delta & -I_{p F} / \Delta \\
-I_{p F} / \Delta & I_{p p} / \Delta
\end{array}\right|
$$

where the determinant of the information matrix is $\Delta=I_{F F} I_{p p}-I^{2}{ }_{\mathrm{pF}}$. So that the variances of $p$ and $F$ are, respectively

$$
\sigma_{p}^{2}=I_{H F} / \Delta \quad \sigma_{F i}^{2}=I_{p p} / \Delta .
$$

The information with respect to the two variables is

$$
\begin{aligned}
& I_{p p}=n\left[\frac{[F+2 p(1-F)]^{2}}{p^{2}+p q F}+\right. \frac{2(1-F)(1-2 p)^{2}}{p q}+ \\
&\left.\frac{[-2+F+2 p(1-F)]^{2}}{q^{2}+p q F}\right] \\
&=n\left[\frac{2 p q(1+F)+F(2-F)(1-2 p)^{2}}{p q(p+q F)(q+p F)}\right] \\
& I_{F F}=n\left[\frac{p q^{2}}{(p+q F)}+\frac{2 p q}{(1-F)}+\frac{p^{2} q}{(q+p F)}\right] \\
&=n\left[\frac{p q(1+F)}{(1-F)(p+q F)(q+p F)}\right] \\
& I_{p F}=n\left[\frac{q[F+2 p(1-F)]}{p+q F}-2(1-2 p)+\right. \\
&\left.\frac{p[-2+F+2 p(1-F)]}{q+p F}\right] \\
&=n\left[\frac{F(p-q)}{(p+q F)(q+p F)}\right]
\end{aligned}
$$

and $\Delta=I_{p p} I_{F F}-I_{p F^{2}}$

$$
=\frac{2 n^{2}}{(1-F)(p+q F)(q+p F)} .
$$

The expression for the variances of the parameters $p$ and $F$ are thus

$$
\begin{aligned}
\sigma_{p}^{2} & =\frac{p q(1+F)}{2 n} \\
\sigma_{F}{ }^{2} & =\frac{(1-F)\left[2 p q(1+F)+F(2-F)(1-2 p)^{2}\right]}{2 n p q} .
\end{aligned}
$$

The standard error of an estimate $(s)$ can thus be calculated by solving the variances $\left(s^{2}\right)$ using the maximum likelihood estimates for the values of $p, q$, and $F$.

\section{Literature Cited}

BlaIR, W. F. 1942. Size of home range and notes on the life history of the woodland deer mouse and eastern chipmunk in northern Michigan. J. Mammal., 23: 27-36.

- 1947. Estimated frequencies of the buff and gray genes $(G, g)$ in adjacent populations of deer-mice (Peromyscus maniculatus blandus) living on soils of different colors. Contrib. Lab. Vert. Biol. Univ. Mich., 36: 1-16.

Cotterman, C. W. 1954. Estimation of gene frequencies in nonexperimental populations. Chapter 35 , p. 449-465. In O. Kempthorne, T. A. Bancroft, J. W. Gowen, and J. L. Lush (ed.), Statistics and mathematics in biology. Iowa State College Press, Ames.

DAHLBERG, G. 1948. Mathematical methods for population genetics. Interscience $\mathrm{Publ}$., New York.

Dice, L. R., AND W. E. Howard. 1951. Distance of dispersal by prairie deer mice from birthplaces to breeding sites. Contrib. Lab. Vert. Biol. Univ. Michigan, 50: 1-15.

Howard, W. E. 1949. Dispersal, amount of inbreeding, and longevity in a local population of prairie deer mice on the George Reserve, southern Michigan. Contrib. Lab. Vert. Biol. Univ. Michigan, 43: 1-50.

KEMPTHORNE, O. 1957. An introduction to genetic statistics. John Wiley and Sons, New York.

Kimura, M. 1956. Rules for testing stability of a selective polymorphism. Proc. Nat. Acad. Sci., 42: 336-340.

LI, C. C. 1955a. Population genetics. Univ. of Chicago Press, Chicago.

- $1955 \mathrm{~b}$. The stability of an equilibrium and the average fitness of a population. Am. Naturalist, 89: 281-296.

— AND D. G. Horvitz. 1953. Some methods of estimating the inbreeding coefficient. Am. J. Human Genet., 5: 107-117.

Manville, R. H. 1949. A study of small mammal populations in northern Michigan, Misc. Publ. Mus. Zool. Univ. Michigan, 73: 1-83.

Neel, J. V., AND W. J. Schull. 1954. Human heredity. Univ. Chicago Press, Chicago.

Rasmussen, D. I. 1961. Erythrocytic antigenic differences between individuals of the deer mouse, Peromyscus maniculatus. Genet. Res., 2: $449-455$.

Schull, W. J., K. P. Ito, ANd A. Sont. (In press). A note on inbreeding and the island of Susak.

Stevens, W. L. 1950. Statistical analysis of the ABO blood groups. Human Biol., 22: 191217.

Wright, S. 1940. Breeding structure of population in relation to speciation. Am. Nat., 74: 232-248.

- 1943. Isolation by distance. Genetics, 28: $114-138$. 
1946. Isolation by distance under diverse systems of mating. Genetics, 31: 39-59.

- 1948. On the roles of directed and random changes in gene frequency in the genetics of population, Evolution, 2: 279-294.
1951. The genetical structure of populations. Ann. Eugenics, 15: 323-354.

- 1960. Physiological genetics, ecology of populations, and natural selection, p. 429-475. In S. Tax (ed.), Evolution after Darwin. Vol. I. Univ, Chicago Press, Chicago. 